\title{
Ecossistemas brasileiros: degradação e potencialidades
}

\section{Brazilian ecosystems: degradation and capabilities}

\section{Ecosistemas brasileños: degradación y capacidades}

http://dx.doi.org/10.21713/2358-2332.2016.v13.1008

Luciano Zanetti Pessôa Candiotto, doutor em Geografia pela Universidade Federal de Santa Catarina (UFSC), professor associado e coordenador do Programa de Mestrado em Geografia da Universidade Estadual do Oeste do Paraná (Unioeste), campus de Francisco Beltrão, PR, Brasil. E-mail: lucianocandiotto@yahoo. com.br.

\section{Resumo}

Na tentativa de contribuir para o debate sobre a utilização dos ecossistemas brasileiros, este artigo aborda elementos relacionados à produção de conhecimentos sobre os ecossistemas e a riqueza natural do Brasil, aspectos de sua degradação, bem como os limites e os potenciais da ciência para o desenvolvimento de pesquisas relacionadas à preservação dos ecossistemas brasileiros e à utilização conservacionista de seus recursos naturais. A análise se fundamentou em referências provenientes de autores ligados à Geografia e à Ecologia Política e em nossa experiência no desenvolvimento de pesquisas e orientações relacionadas à questão ambiental. Conclui-se que, nesse debate, além da dimensão científica e técnica, é preciso levar em consideração a dimensão política, haja vista que ela exerce forte influência sobre as causas e consequências da utilização dos ecossistemas brasileiros.

Palavras-chave: Ecossistemas. Brasil. Ciência. Política. Gestão. 


\section{Abstract}

As an attempt to contribute to the debate on the use of Brazilian' ecosystems, this article discusses elements related to the production of knowledge on Brazil's ecosystems and natural wealth, aspects of degradation, as well as science's limitations and potentials related to the development of research on preservation and conservational use of Brazilian ecosystems and their natural resources. This analysis was based on references from authors linked to Geography and Political Ecology, and our experience in the development of research and orientation related to environmental issues. It was concluded that, in addition to the scientific and technical dimension, the political dimension must be included in the debate due to its strong influence on the causes and consequences of Brazilian ecosystemśuses.

Keywords: Ecosystems. Brazil. Science. Politics. Management.

\section{Resumen}

En el intento de contribuir al debate sobre el uso de los ecosistemas brasileños, este artículo describe los elementos relacionados con la producción de conocimiento sobre los ecosistemas y la riqueza natural de Brasil, aspectos de su degradación así como los límites y las posibilidades de la ciencia para el desarrollo de investigaciones relacionadas con la preservación de los ecosistemas brasileños y la conservación de sus recursos naturales. El análisis se basa en las referencias de autores vinculados a la Geografía y Ecología Política, y en nuestra experiencia acerca del desarrollo de investigaciones y orientaciones relacionadas con cuestiones ambientales. Se concluye que, además de la dimensión científica y técnica, hay que tener en cuenta la dimensión política en este debate en razón de su fuerte influencia sobre las causas y consecuencias de la utilización de los ecosistemas brasileños.

Palabras clave: Ecosistemas. Brasil. Ciencia. Política. Gestión. 


\section{INTRODUÇÃo}

No contexto de nossa formação e atuação dentro da graduação e da pós-graduação em Geografia, o debate acerca da relação naturezasociedade tem permeado reflexões, aulas, orientações e pesquisas que temos desenvolvido, seja na análise de eventos relacionados à degradação ambiental, seja no estudo e na tentativa de contribuição para expansão e fortalecimento de formas de uso conservacionista dos ecossistemas brasileiros e de seus recursos naturais.

Nesse sentido, ao ter conhecimento sobre a edição especial intitulada Ecossistemas brasileiros: potenciais de desenvolvimento, da Revista Brasileira de Pós-Graduação (RBPG), buscamos expressar nossa posição no sentido de contribuir para o debate dessa temática tão relevante e desafiadora para pesquisadores brasileiros de diversas áreas do conhecimento.

Certamente, existem diferentes maneiras de interpretar e posicionar-se sobre esse amplo tema, que varia conforme as áreas de formação e atuação dos pesquisadores, bem como conforme suas concepções sobre ciência, técnica, natureza, meio ambiente, política e desenvolvimento. Sabendo das limitações de nossa interpretação, objetivamos com este texto apenas problematizar algumas questões e, quem sabe, aguçar a reflexão de outros colegas, em virtude de tratar-se de tema interdisciplinar.

Este artigo objetiva discorrer a respeito de elementos atinentes a uma breve trajetória da produção de conhecimentos sobre os ecossistemas brasileiros, riqueza natural brasileira, aspectos de degradação dos ecossistemas brasileiros, limites e potenciais da ciência e pós-graduação para o desenvolvimento de pesquisas relacionadas à preservação dos ecossistemas brasileiros e à utilização conservacionista de seus recursos naturais. Para tanto, utilizaram-se referências provenientes, sobretudo, de autores ligados à Geografia e à Ecologia Política, que fundamentam nossas concepções teóricas, metodológicas e ideológicas relacionadas às perspectivas de utilização conservacionista dos ecossistemas brasileiros. 


\section{DESENVOLVIMENTO}

\subsection{Antecedentes históricos do conceito de ecossistema e dos estudos no Brasil}

Desde o período do descobrimento do Brasil por portugueses e outros europeus a partir do século XV, a referência à riqueza natural do país foi alvo de destaque por parte de colonizadores e naturalistas.

Naturalistas como Humboldt, Spix e Von Martius ${ }^{1}$ aportaram em terras brasileiras, levando importantes informações e conhecimentos sobre as paisagens e a biodiversidade brasileiras. Desde as expedições colonizadoras capitaneadas pelos portugueses até as expedições dos naturalistas financiadas por outros reinos europeus, a prioridade estava na descoberta de novas terras, novas plantas, animais e minerais que poderiam ser úteis como: fonte de alimento, medicamento, ferramenta, vestuário e outros produtos. Assim, apesar de a finalidade científica inerente às expedições naturalistas, elas eram motivadas por intencionalidades econômicas e políticas, conforme salientado por Porto-Gonçalves (2012).

Com o avanço do processo de colonização e das expedições naturalistas no Brasil, os conhecimentos científicos sobre a natureza local também foram intensificados. No entanto, para a coroa portuguesa, responsável pelo processo de colonização, interessavam muito mais a

${ }^{1}$ Von Martius foi responsável pela primeira classificação fitogeográfica brasileira, em 1824. Posteriormente, outras classificações foram elaboradas, com destaque para a do Projeto Radam, na década de 1970, e a de George Eiten, em 1983 (AB'SABER, 2006).

2 Tansley, em 1935, definiu ecossistema como o sistema ecológico de um lugar. Os ecossistemas ocorrem no interior de uma área ampla, "[...] representativa de um domínio regional ou macrorregional de natureza (bioma ou domínio morfoclimático e fitogeográfico)." (AB'SABER, 2006, p. 266) exploração dos recursos naturais existentes e a subjugação das etnias indígenas do que estudos e pesquisas sobre a exuberante natureza brasileira.

Até a década de 1930, período em que o conceito de ecossistema² foi elaborado e incorporado entre cientistas, focava-se na identificação de espécies animais, plantas e outros seres vivos por meio de inventários da biodiversidade. Assim, os naturalistas atuavam com método descritivo da natureza, procurando catalogar, classificar e conhecer cada espécie encontrada. Por outro lado, eles se preocupavam também em propor, comprovar ou refutar determinadas teorias, com o objetivo de conhecer determinadas leis gerais da natureza. 
Com a adoção da Teoria Geral dos Sistemas proposta por Bertalanffy em 1968, surge uma nova teoria científica, pautada na interação entre as partes e não somente na explicação do todo pela soma das partes. Da mesma forma, com a incorporação do conceito de ecossistema na Ecologia e em outras ciências correlatas, inicia-se um processo de busca de explicações da integração e da interdependência existente entre os seres vivos, assim como entre os elementos bióticos (seres vivos) e abióticos (rochas, corpos hídricos, gases). A visão sistêmica passa a ser paulatinamente incorporada em pesquisas direcionadas ao entendimento da estrutura e do funcionamento dinâmico da natureza, por meio do conceito de ecossistema.

A palavra "eco" corresponde a toda a vida, enquanto "sistema" refere-se aos vínculos existentes entre os fatores abióticos (rochas, minerais dos solos, águas) e bióticos (vida aeróbica e anaeróbica, flora, fauna e microrganismos). Cada ecossistema implica a combinação de três componentes: 1) suporte ecológico (aspectos geológicos e geomorfológicos); 2) composição biótica (plantas, animais e outros seres vivos); 3) condições climáticas que justificam a permanência das formas de vida existentes no ecossistema (solos, águas, nutrientes) (AB'SABER, 2006).

Assim, o ecossistema corresponde ao:

Conjunto integrado de fatores físicos, ecológicos e bióticos que caracterizam um determinado lugar, estendendo-se por um espaço de dimensões variáveis. É uma totalidade integrada e sistêmica, que envolve fatores abióticos e bióticos, em sua funcionalidade e processos metabólicos. (ACIESP, 1997, p. 86).

Apesar de o conceito de ecossistema ser fundamentado em um enfoque ecológico-biológico, Porto-Gonçalves (2012) alerta para a importância da cultura de diferentes grupos étnicos na configuração dos ecossistemas. Ao considerar a presença do ser humano no Brasil nos últimos 12 mil anos, o autor enfatiza a introdução de plantas e animais na Amazônia, na Mata Atlântica e em outros biomas e ecossistemas brasileiros. 
Portanto, boa parte da área dos ecossistemas brasileiros já sofreu alguma interferência antrópica, sobretudo no que tange seus elementos bióticos, direta ou indiretamente, seja pela presença de grupos étnicos antigos, principalmente compostos por indígenas, seja pela exploração e ocupação promovida pelos colonizadores portugueses. Ao longo do tempo, a introdução de espécies de plantas e animais - bem como alterações químicas na atmosfera, nos solos e nos corpos d'água - tem sido cada vez mais intensa.

Durante a segunda metade do século XX, o conhecimento sobre a estrutura e o funcionamento dos ecossistemas ampliou-se, principalmente nos países ricos, que possuem condições econômicas e políticas favoráveis ao desenvolvimento científico. Destacam-se os países europeus (Alemanha, Inglaterra e França), os Estados Unidos e o Japão, que, para Amin (2001), formam a tríade do poder geopolítico mundial. Nos países considerados periféricos - como o Brasil - os avanços foram bem mais tímidos, de modo que boa parte do conhecimento científico produzido sobre eles tem sido historicamente realizada por pesquisadores dos países centrais.

No Brasil, a maior parte dos avanços científicos da segunda metade do século XX deu-se em áreas vinculadas a energia elétrica (petróleo e hidrelétricas), rodovias, transportes, mineração, agricultura e construção civil, de modo que as engenharias prevaleceram sobre outras áreas. 0 conhecimento técnico foi priorizado pelo Estado - por intermédio de investimentos públicos -, ao contrário daqueles conhecimentos atinentes à sociedade ou à natureza. Isso se reflete no incipiente conhecimento sobre nossos ecossistemas.

Com relação à produção de conhecimentos sobre a natureza, é possível afirmar que as pesquisas relacionadas a minerais e rochas, voltadas à extração mineral, e as pesquisas relacionadas às águas, voltadas à navegação e utilização de água para abastecimento humano, agricultura e produção de energia elétrica, tiveram incentivos bem maiores que as pesquisas direcionadas ao conhecimento sobre a dinâmica dos ecossistemas e dos seus elementos bióticos. 0 enfoque estava nos recursos naturais, e não no ecossistema como totalidade, denotando a 
fragmentação da ciência e o histórico predomínio da dimensão econômica na utilização da natureza e na configuração do espaço geográfico.

Por conseguinte,

[...] um levantamento qualitativo e quantitativo extensivo e preciso dos ecossistemas naturais brasileiros é algo ainda por ser alcançado pela ciência, tamanha a variedade, complexidade e dimensão dos ambientes naturais e originais encontrados no Brasil. (AB'SABER, 2006, p. 62).

Bohrer e Dutra (2009) indicam algumas lacunas que devem ser superadas em termos de conhecimento da biodiversidade brasileira: a) existência de espécies ainda não descobertas e identificadas pela ciência; b) dificuldade em mensurar a biodiversidade; c) pouco conhecimento sobre a relação entre a biodiversidade e o funcionamento dos ecossistemas e; d) necessidade de conhecer diferentes escalas espaciais da biodiversidade para definir prioridades de conservação e manejo.

Exemplos históricos da concepção utilitarista da natureza estão nos chamados: Código Florestal, Código de Minas e Código das Águas. Todos eles foram instituídos no ano de 1934, com o objetivo de regulamentar a extração e o uso de recursos naturais (CUNHA; COELHO, 2003). Ainda na década de 1930, o governo federal instituiu as primeiras áreas protegidas do Brasil (parques nacionais e reservas florestais). Contudo, a seleção de áreas para implantação de parques nacionais estava fundamentada em aspectos estéticos (belas paisagens) (DIEGUES, 1994) e na possibilidade de uso turístico destas áreas.

A maior rigidez em termos de proteção florestal ocorreu somente com o Código Florestal, modificado em 1965 (Lei n 4.771, de 15 de setembro de 1965), por meio da instituição das Áreas de Preservação Permanente e das Reservas Legais. No entanto, esta lei não foi devidamente cumprida ao longo dos anos, o que intensificou o processo de desmatamento no Brasil, que permanece até os dias atuais. Outro fator agravante está na flexibilização da legislação florestal brasileira, por intermédio da promulgação do novo Código Florestal de 2012 (Lei nº 12.651, de 25 de maio de 2012). 
Na década de 1970, os países do Sul passaram a ser mais pressionados com relação à institucionalização de órgãos de proteção e gestão ambiental após a Conferência Internacional sobre Meio Ambiente e Desenvolvimento, promovida pela Organização das Nações Unidas (ONU) no ano de 1972 em Estocolmo. No Brasil, tal pressão levou à criação da Secretaria Especial de Meio Ambiente (Sema)³, no ano de 1973, e à intensificação das normas atinentes à preservação da natureza e à gestão do meio ambiente.

Na década de 1980, destacam-se outros avanços relevantes no tocante à legislação e à política ambiental brasileira. No ano de 1981, a Lei 6.938 institui a Política Nacional do Meio Ambiente, considerada um marco da proteção ambiental no Brasil. Apesar de esta lei enfatizar a importância do equilíbrio ecológico, da qualidade ambiental e da sua compatibilização com o desenvolvimento econômico-social, a única referência específica ao termo "ecossistema" aparece em um dos princípios da política nacional, referente à "proteção dos ecossistemas, com a preservação de áreas representativas" (BRASIL, 1981, artigo $2^{\circ}$, IV).

Em 1986, o Conselho Nacional de Meio Ambiente publicou sua primeira resolução, estabelecendo a obrigatoriedade dos Estudos de Impacto Ambiental (EIA) e dos Relatórios de Impacto Ambiental (RIMA) para empreendimentos considerados de grande porte. Em 1988, a Constituição Federal teve capítulo específico para o meio ambiente, no qual se especifica que uma das funções do poder público é "preservar e restaurar os processos ecológicos essenciais e prover o manejo ecológico das espécies e ecossistemas" (BRASIL, 1988, artigo 225, §1, I). Neste mesmo capítulo, define-se que:

A Floresta Amazônica brasileira, a Mata Atlântica, a Serra do Mar, o Pantanal Mato-Grossense e a Zona Costeira são patrimônio nacional, e sua utilização far-se-á, na forma da lei, dentro de condições que assegurem a preservação do meio ambiente, inclusive quanto ao uso dos recursos naturais. (BRASIL, 1988, artigo 225, §4').

${ }^{3}$ Posteriormente, em 1989, a SEMA foi transformada no IBAMA (Instituto Brasileiro do Meio Ambiente e dos Recursos Naturais Renováveis). 
os pampas e a caatinga. De qualquer forma, o reconhecimento legal é relevante 4 , mas não garante ações efetivas de preservação e manejo sustentável desses ecossistemas considerados prioritários.

\subsection{A riqueza biofísica do Brasil e seu reconhecimento}

Mittermeier et. al. (1997 apud BOHRER; DUTRA, 2009) destacam a relevância do Brasil no contexto dos países com megadiversidade no planeta, por possuir o maior número de espécies de angiospermas (55 mil), mamíferos (524) e peixes de água doce (mais de 3 mil), além de ser o segundo país com maior biodiversidade de espécies de anfíbios (517) e de ser o terceiro em aves (1.622) e o quinto em répteis (468). Aos altos níveis de biodiversidade, aliam-se altos níveis de endemismo.

Vários pesquisadores foram fundamentais para o levantamento geoecológico e biológico brasileiro. No âmbito da Geografia brasileira, uma das referências clássicas é o trabalho de Aziz Ab'Saber. Entre outras importantes contribuições, Ab'Saber elaborou o conceito de "domínios morfoclimáticos" e "províncias fitogeográficas", entendido como:

[...] um conjunto espacial de certa ordem de grandeza territorial de centenas de milhares a milhões de $\mathrm{Km}^{2}$ de área - onde haja um esquema coerente de feições de relevo, tipos de solos, formas de vegetação e condições climático-hidrológicas (AB'SABER, 2003, p. 12).

Por meio do conceito de "espaço-total", Ab'Saber também procurou estabelecer análise integrada entre os elementos naturais e humanos, entendendo que antes do ser humano existia a natureza, porém, que ela é hoje amplamente influenciada pelas ações humanas, sobretudo pela degradação ambiental e social decorrente de interesses individuais e corporativistas, que se sobrepõem aos interesses coletivos.

Ab'Saber identificou seis grandes domínios paisagísticos e macroecológicos no Brasil, sendo quatro intertropicais, com área de 7,5 milhões de $\mathrm{Km}^{2}$, e dois subtropicais, com área de 0,5 milhões de $\mathrm{Km}^{2}$ (Quadro 1). Sabendo da impossibilidade de traçar "limites lineares" entre

${ }^{4}$ Milaré (2007) é autor de obra detalhada sobre o direito ambiental brasileiro. 
cada um dos grandes domínios morfoclimáticos e ecológicos do Brasil, Ab'Saber reconheceu também a existência de faixas de transição entre eles.

Quadro 1 - Domínios morfoclimáticos e ecológicos do Brasil

\begin{tabular}{|l|l|l|}
\hline \multicolumn{1}{|c|}{ DOMínIO } & ÁREA (Km²) & $\begin{array}{r}\text { BIOMA/ } \\
\text { ECOSSISTEMA } \\
\text { CORRESPONDENTE }\end{array}$ \\
\hline $\begin{array}{l}\text { Terras baixas florestadas da } \\
\text { Amazônia }\end{array}$ & 2.500 .000 & Amazônia \\
\hline $\begin{array}{l}\text { Depressões interplanálticas } \\
\text { semi-áridas do Nordeste }\end{array}$ & 850.000 & Caatinga \\
\hline Mares de morros florestados & 1.000 .000 & $\begin{array}{l}\text { Mata Atlântica } \\
\text { Ecossistemas costeiros } \\
\text { (mangues, dunas). }\end{array}$ \\
\hline $\begin{array}{l}\text { Chapadões recobertos e penetrados } \\
\text { por floresta-galeria }\end{array}$ & 2.000 .000 & $\begin{array}{l}\text { Cerrado } \\
\text { Ecossistemas de campos, } \\
\text { campinas e campestres }\end{array}$ \\
\hline Planaltos de araucárias & 400.000 & Mata Atlântica \\
\hline $\begin{array}{l}\text { Pradarias mistas do sudeste do Rio } \\
\text { Grande do Sul }\end{array}$ & 80.000 & Pampas \\
\hline Faixas de transição & 1.670 .000 & $\begin{array}{l}\text { Pantanal matogrossense } \\
\text { Mata dos cocais } \\
\text { Outros ecossistemas }\end{array}$ \\
\hline
\end{tabular}

Fonte: Ab'Saber (2003; 2006).

Ao sediar a II Conferência Internacional sobre Meio Ambiente e Desenvolvimento da ONU, em 1992, o Brasil passou a ser reconhecido mundialmente como um dos países com maior biodiversidade de ecossistemas e espécies do planeta, mas também com grande diversidade de problemas ambientais. O bioma Amazônia foi o mais destacado, porém diversos alertas sobre as consequências nefastas do desmatamento da Amazônia e de outros ecossistemas florestais também foram alvo dos debates desta conferência.

Durante e após a Rio-92, ecoou no Brasil o reconhecimento internacional da riqueza ecossistêmica e biológica brasileira, bem como de seu potencial e de sua importância no contexto do desenvolvimento sustentável. Este reconhecimento - propagado pela mídia - levou a um 
despertar por parte da população brasileira sobre esta riqueza e sobre a necessidade de ações direcionadas a sua preservação e a sua conservação. Assim, a natureza tornou-se objeto de orgulho dos brasileiros.

Todavia, esse orgulho tem contrastado com a triste realidade de degradação ambiental decorrente de: diversas ações nefastas; falta de políticas públicas e de aplicação de normas para frear tal degradação e efetivar usos conservacionistas e ações preservacionistas; incipiente conhecimento científico sobre a dinâmica dos ecossistemas, que tem relação com a falta de investimentos em pesquisas científicas; e, manutenção de modelo de desenvolvimento pautado na extração de recursos naturais e na produção de bens primários. Não obstante, esta problemática tem dificultado ações amplas em busca do desenvolvimento sustentável, que também se tornou discurso vago e utilizado com diversas intencionalidades 5 .

\begin{abstract}
[...] o maior problema sobre a compreensão da complexidade ecossistêmica da natureza brasileira ocorre quando somos levados a considerar a crescente ação de expansão dos agroecossistemas e ecossistemas urbanos sobre as áreas naturais, antes dominantes e agora, em várias regiões, apenas remanescentes. Por tais razões, estudos sobre os ecossistemas no Brasil se tornam cada vez mais necessários e urgentes, ante a crescente diminuição das áreas naturais efetivamente preservadas em termos ecológicos e ambientais (AB'SABER, 2006, p. 62).
\end{abstract}

Outra lacuna científica apresentada por Bohrer e Dutra (2009) está no predomínio de estudos limitados a apenas alguns componentes do sistema, em detrimento de estudos que permitam considerar todo o sistema ecológico como uma unidade. Para tanto, os autores enfatizam a necessidade de incentivo a abordagens interdisciplinares e holísticas na busca de soluções de problemas reais relacionados à conservação e ao uso sustentado dos ecossistemas e dos recursos naturais brasileiros.

Portanto, além das dificuldades já existentes em termos da falta de estudos - específicos e integrados - sobre os ecossistemas naturais, há também a problemática da redução das áreas naturais remanescentes, em virtude do agronegócio (agricultura e pecuária), da mineração, da ocupação
${ }^{5}$ Leff (1998), Gudynas (2004) e Porto-Gonçalves (2012) são alguns pesquisadores críticos ao conceito de desenvolvimento sustentável e à sua ampla utilização nos mais variados discursos. 
urbana e de outras atividades econômicas ${ }^{6}$, dificultando a possibilidade de pesquisas sobre a estrutura e a dinâmica de funcionamento dos ecossistemas brasileiros.

\subsection{A ligação entre ciência e política}

No contexto da Geografia e de outras ciências sociais, o conceito de território tem sido amplamente utilizado, por implicar relações de poder e incorporar a dimensão política como elemento relevante nas relações sociais e nas próprias relações estabelecidas entre indivíduos e grupos sociais com a natureza e o ambiente. Nesse sentido, a análise a respeito de conflitos ambientais promovida no âmbito da Ecologia Política (ALIER, 2015; GUDYNAS, 2004) também tem a dimensão política (de relações de poder) como elemento central para a interpretação da problemática ambiental.

Na Geografia contemporânea, Raffestin (1993) é um dos principais autores que têm debatido a relação entre território e poder. Sua grande contribuição foi ampliar o enfoque de território para além do Estado-nação, associando-o a todas as formas de poder. Ao afirmar que a Geografia Política clássica foi trabalhada simplesmente como "Geografia do Estado", deixando de abstrair outras formas de poder, Raffestin inclui novas variáveis em sua tentativa de sistematizar uma "Geografia do Poder", diferenciando o poder da seguinte forma: a) o Poder, que é facilmente identificável, por ser manifestado mediante os aparelhos institucionais do Estado; b) o poder, presente em cada relação, que é muitas vezes invisível, por conseguinte mais perigoso e difícil de ser identificado. Ambos exercem influência sobre o controle da população e o domínio dos recursos naturais.

O território expressa relação direta entre poder e sua configuração e materialização espacial. Nele e, por meio dele, estão embutidas relações políticas, econômicas e culturais que definem o espaço geográfico.

${ }^{6}$ Dean (1996) e Ross (2003) apresentam detalhes sobre o processo histórico de ocupação e degradação ambiental no Brasil.
Souza (1995, p. 81) alerta que "[...]os territórios são construídos e desconstruídos nas mais diversas escalas espaciais e temporais." Haesbaert (2004, p. 97) reforça essa ideia, ao afirmar que o poder, por 
conseguinte, o território "[...] é sempre multidimensional e multiescalar, material e imaterial, de dominação e apropriação ao mesmo tempo [...]", e aponta a

[...] necessidade de uma visão de território a partir da concepção de espaço como um híbrido - hỉbrido entre sociedade e natureza, entre política, economia e cultura, e entre a materialidade e a idealidade numa complexa interação espaço-tempo. (HAESBAERT, 2004, p. 79).

Portanto, o território corresponde a uma combinação da dimensão material com a simbólica, envolvendo elementos naturais, objetos técnicos, ações, intencionalidades, dinâmica econômica, representações culturais e, principalmente, relações de poder.

O entendimento sobre a chamada questão ambiental - que envolve diversos eventos e problemas decorrentes da relação entre sociedade e natureza - não se explica somente no plano científico e técnico. Nesse sentido, Candiotto (2013) ressalta a relevância do conceito de território e a da dimensão política para apreender as causas e consequências da utilização do ambiente por parte de indivíduos e grupos sociais. Seja na escala global, seja em escalas menores (país, estados e municípios, entre outras), o incentivo, a aceitação e a incorporação de conhecimentos científicos e de técnicas no processo de planejamento e gestão - como a realização de inventários e diagnósticos de elementos da natureza; a análise e a busca de redução da degradação ambiental; a efetivação de estratégias e ações de preservação e utilização conservacionista de paisagens, ecossistemas, espécies e outros elementos da natureza e do ambiente - depende, sobretudo, de decisões políticas, engendradas por relações de poder.

Dessa forma, a percepção, os problemas e as soluções ambientais, analisados sob o prisma de uma relação dialética natureza-sociedade, estão permeados pela dimensão político-territorial (CANDIOTTO, 2013).

Esta dimensão política da questão ambiental se dá desde escalas macroterritoriais, envolvendo territorialidades de grandes firmas, até escalas microterritoriais, ligadas a territorialidades vividas no cotidiano de pessoas e grupos sociais. Contudo, esta relação 
é multiescalar, pois o global, o local e outras escalas possíveis coexistem nos lugares. (CANDIOTTO, 2013, p. 158).

Para exemplificar tal perspectiva, Candiotto (2013) discorre sobre a ampla utilização - com vieses bem distintos - do conceito de desenvolvimento sustentável, utilizado por instituições financeiras, corporações transnacionais, governos, políticos, movimentos sociais, ONG, cientistas, jornalistas e outros sujeitos sociais, para promover ou justificar discursos que muitas vezes são totalmente contraditórios. Outro exemplo citado a respeito da importância da dimensão política no campo ambiental é o processo de planejamento e gestão ambiental, haja vista que a simples existência de normas ambientais não garante gestão conservacionista e fundamentada em planejamento e monitoramento comprometidos com a aplicação de conhecimentos científicos? .

A recente polêmica em torno do novo Código Florestal brasileiro (Lei 12.651/12) é outro exemplo de como a dimensão política interfere na utilização de nossos ecossistemas. A flexibilização das exigências de Áreas de Preservação Permanente (APP) - traduzida na redução de APP em margens de cursos d'água em comparação com o Código Florestal de 1965 e no conceito de "área rural consolidada" - ocorreu sem debate científico amplo, conforme alertado em três publicações destacadas pela Fundação de Amparo à Pesquisa do Estado de São Paulo (FAPESP, 2010). Uma delas foi uma carta redigida por pesquisadores ligados ao Programa Biota-Fapesp, publicada na revista Science em 16 de julho de 2010. Outra carta foi elaborada pela Sociedade Brasileira para o Progresso da Ciência (SBPC) e pela Academia Brasileira de Ciências (ABC) em 25 de junho de 2010, entregue ao então relator da Comissão Especial do Código Florestal Brasileiro, deputado federal Aldo Rebelo. Dias depois - em 27 de junho de 2010 - , o geógrafo Aziz Ab'Saber publicou mais uma carta, intitulada "Do Código Florestal para o Código da Biodiversidade", publicada no site da SBPC.

${ }^{7} \mathrm{O}$ artigo de Oliveira (2012) aborda a baixa qualidade de estudos de impacto ambiental, relatórios de impacto ambiental e outros documentos relativos ao processo de licenciamento ambiental no Brasil.
Apesar de a mobilização da comunidade científica brasileira, prevaleceram os interesses de determinados grupos políticos, sobretudo dos vinculados aos setores ruralistas e do agronegócio. Além disto, cabe ressaltar a lentidão na implementação do Cadastro Ambiental Rural e dos programas de regularização ambiental, não concluídos até hoje. 
Certamente, essa dimensão política da questão ambiental tem íntima relação com intencionalidades econômicas (CANDIOTTO, 2013; PORTO-GONÇALVES, 2012). O próprio processo de privatização da ciência, ou de produção científica atrelada a interesses empresariais e corporativistas, tem sido alvo de críticas por parte de geógrafos, sociólogos, filósofos e outros cientistas sociais.

Por outro lado, o direcionamento de políticas públicas nas áreas de ciência e tecnologia, por meio de normas e editais de financiamento de pesquisas, também está atrelado à dimensão política e econômica. Assim, refletir sobre prioridades da pesquisa científica e da produção em nível de pós-graduação implica levar em consideração essas questões.

Em termos de gestão de ecossistemas, as possibilidades com relação à: otimização de usos conservacionistas, como manejo florestal, agroflorestal e agroecológico; criação e gestão de unidades de conservação; cumprimento de diversas normativas (leis, decretos, resoluções etc.) atinentes a planejamento e a gestão ambiental; elaboração e execução de planos diretores; valorização de saberes tradicionais; entre outras; esbarram muitas vezes em interesses econômicos e políticos de setores vinculados a agronegócio, mineração, energia, mercado imobiliário, empreiteiras etc., que geralmente estão atrelados aos interesses hegemônicos de grandes corporações transnacionais (empresas), conforme apontado por Porto-Gonçalves (2012) e Santos (1996). Por sua vez, diversos representantes políticos (vereadores, prefeitos, deputados estaduais e federais, governadores e senadores) têm suas campanhas eleitorais financiadas por empresas, ampliando o vínculo entre poder econômico e poder político no Brasil.

Esse poder destacado das corporações transnacionais também traz como consequência diversas formas de exploração nefasta dos recursos naturais e dos ecossistemas brasileiros. Exemplo marcante está na expansão do agronegócio, mediante o desmatamento de áreas para criação de animais e produção de grãos - com destaque para soja e milho (sendo que boa parte dessa produção é transgênica) - , a consequente perda de biodiversidade e de fertilidade dos solos, e a intensificação do uso de agrotóxicos no Brasil. 
De modo geral, o predomínio do modelo de desenvolvimento vigente durante os séculos XIX e XX, pautado na lógica do crescimento econômico e no aumento do produtivismo e do consumismo, tem ampliado a demanda por recursos naturais e, consequentemente, sua exploração. O problema é que existem recursos naturais esgotáveis, ou seja, que não são renováveis ou demoram muito tempo para se formar, como os solos, as fontes de petróleo e os minérios.

Considerando a enorme disparidade no acesso aos recursos e às mercadorias, em virtude do próprio modo de produção capitalista - que se fundamentam na acumulação privada da riqueza, gerada muitas vezes a partir de bens coletivos - fica nítido que um dos grandes problemas contemporâneos está na desigualdade social. Assim, há uma ideologia do desenvolvimento que prioriza a dimensão econômica em detrimento das dimensões social e ambiental.

Apresentar o velho e questionável discurso de que o crescimento econômico automaticamente conduz ao desenvolvimento social leva à impressão de que não há outra via para o desenvolvimento (PORTOGONÇALVES, 2012). A apropriação privada de bens coletivos, como 0 solo e a água, bem como a "devolução" para toda a sociedade de passivos ambientais (poluição do ar, contaminação dos recursos hídricos, perda de fertilidade de solos, redução da biodiversidade etc.) demonstra como esse modelo é insustentável e degradador. A fórmula é simples: utiliza-se de bens coletivos para produzir riqueza, que por sua vez é apropriada por agentes privados, como empresários, especuladores e políticos corruptos. Os benefícios são privatizados enquanto os prejuízos são socializados, principalmente entre os mais pobres.

0 modelo de desenvolvimento vigente incentiva atividades poluentes, apesar de avanços na legislação voltada ao controle da poluição e de outros aspectos de degradação ambiental. No entanto, se a legislação não é aplicada e se os poluidores não são punidos (fatos comuns no Brasil), não há problema em continuar poluindo e degradando o meio ambiente. Apesar de o Brasil ter boa legislação ambiental, existem dificuldades econômicas, políticas e técnicas que impedem a implantação de ações de controle das atividades degradadoras e, principalmente, a punição dos responsáveis pela maior parte dos passivos ambientais. 
Na tentativa de mascarar essas facetas do processo de desenvolvimento e de degradação ambiental, setores responsáveis por essa degradação passam a utilizar o discurso do desenvolvimento sustentável para demonstrar que estão preocupados com o meio ambiente. Bancos, empresas transnacionais, especuladores financeiros e imobiliários, indústrias e o próprio poder público buscam "vender" a imagem de que são sustentáveis, de que estão preocupados com o "futuro do planeta" e de que vêm agindo de forma intensiva para atingir o desenvolvimento sustentável. Porém, é preciso questionar: quais as reais intencionalidades mascaradas nesse discurso da sustentabilidade? As práticas realizadas condizem com o discurso que passou a ser predominante nos últimos anos? Essas ações que se dizem sustentáveis no plano ambiental também estão preocupadas com a redução dos problemas sociais, com destaque para as desigualdades?

Como o próprio conceito de desenvolvimento sustentável institucionalizado pela ONU não questiona o crescimento econômico e seus limites, fica difícil acreditar que estamos caminhando em direção a um novo modelo de desenvolvimento ou a um questionamento do "economicismo", que até o momento é e tende a permanecer como modelo hegemônico de desenvolvimento.

\subsection{Apontamentos acerca de possibilidades de pesquisa}

Sabemos que falar sobre problemas e desafios relacionados à questão ambiental é algo bastante amplo, pois o próprio entendimento do que seja meio ambiente e questão ambiental é heterogêneo e complexo. No entanto, nos propusemos a discutir, de forma sucinta, três grandes temas de interesse da comunidade científica, que envolvem os processos de degradação, preservação e conservação de paisagens e ecossistemas: 1) importância de inventários e diagnósticos para ampliar o conhecimento científico; 2) análises de empreendimentos e atividades com potencial de impacto ambiental e dos próprios estudos destinados ao licenciamento ambiental; 3) análise e implantação de ações voltadas à preservação e usos conservacionistas da natureza e de seus recursos. 
Partimos do pressuposto de que tais temas têm sido abordados de forma pontual, entre cada área específica do conhecimento e entre os pesquisadores, apesar de o aumento de iniciativas interdisciplinares. Salientamos a necessidade de expansão de pesquisas de caráter multi e interdisciplinar, por meio de políticas públicas que incentivem e financiem tais pesquisas. Sabemos que os esforços nesse sentido vêm sendo ampliados, podendo ser evidenciados mediante a existência de diversos programas de pós-graduação interdisciplinares, de editais de financiamento que têm valorizado pesquisas e ações de extensão interdisciplinares, e de programas e projetos de pesquisa interdisciplinares, como é o caso do Programa Biota-Fapesp, direcionado ao desenvolvimento de pesquisas em caracterização, conservação, restauração e uso sustentável da biodiversidade do estado de São Paulo.

No entanto, uma política de ciência e tecnologia direcionada à otimização de ações interdisciplinares de pesquisa e extensão ${ }^{8}$ seria extremamente salutar para o diálogo e a troca de conhecimentos entre os pesquisadores de diferentes áreas do conhecimento, bem como para o avanço no manejo e na gestão sustentável dos ecossistemas brasileiros. Isso contribuiria para o fortalecimento de usos conservacionistas, bem como para evidenciar a necessidade de redução de práticas depredatórias dos ecossistemas, da biodiversidade e dos recursos naturais.

Entendemos que, a partir de bons levantamentos e análises, é possivel conhecer a dinâmica do meio biofísico e aplicar tal conhecimento na utilização dos ecossistemas (considerando a natureza e a sociedade de forma interativa), por meio de ações de planejamento e gestão ambiental e territorial que sejam eficazes na promoção de usos mais adequados dos recursos naturais e na redução dos impactos ambientais e sociais

8 Com relação às ações de extensão, é preciso considerar que as universidades podem contribuir com outras instituições, porém possuem papel limitado nesse sentido. Cabe às instituições - sejam elas públicas, privadas, ONG ou movimentos sociais - estabelecer possiveis parcerias com as universidades e dar continuidade às ações desenvolvidas. existentes.

2.4.1 A importância de inventários e diagnósticos para ampliar o conhecimento científico

A realização de diagnósticos e análises dos ecossistemas pressupõe a junção entre as denominadas pesquisas de base e pesquisas aplicadas. Pesquisa de base pressupõe algo que não necessariamente 
possui aplicabilidade direta, como o conhecimento da evolução física e biológica de paisagens, ecossistemas e espécies. Essas pesquisas são fundamentais para o desenvolvimento das chamadas pesquisas aplicadas, pois sem esses levantamentos e classificações se torna difícil e precária a definição de estratégias de planejamento e gestão em qualquer área geográfica ou ecossistema.

Focando nas pesquisas ambientais, podemos citar como exemplos de pesquisa aplicada um levantamento sobre o uso do solo de determinada área, que objetiva indicar as áreas mais frágeis que possam ser gerenciadas de forma mais adequada; uma análise da qualidade das águas de um rio, que objetiva verificar a situação dessas águas, as possíveis fontes de contaminação e as possibilidades de minimizar o problema; ou outros estudos, que identifiquem problemas ambientais existentes em determinado recorte espacial (um município, um ecossistema, uma bacia hidrográfica etc.) e apontem ações para melhoria da qualidade ambiental e social.

Um desafio para pesquisadores e estudantes de pós-graduação é realizar bons diagnósticos, que consigam integrar informações e que permitam melhorar o processo de planejamento e de gestão ambiental, seja em bacias hidrográficas, ecossistemas ou outra unidade de análise. Para a realização dos levantamentos básicos e dos diagnósticos, existem metodologias e técnicas diversas. As técnicas de geoprocessamento, sensoriamento remoto e fotointerpretação possibilitam a espacialização das informações, contribuindo na obtenção de dados de difícil coleta em campo, e também no mapeamento de dados produzidos com outras metodologias. Os trabalhos de campo também são de suma importância para o levantamento de informações primárias, fundamentais para a realização dos diagnósticos.

Os levantamentos e diagnósticos constituem amplo objeto de pesquisas e são ferramentas imprescindiveis no processo de planejamento e gestão. No entanto, no Brasil ainda há grande dificuldade em criar uma "cultura do planejamento", para a qual são necessários investimentos em pesquisas científicas e em sua aplicação. 
Apesar de não existir tal cultura, não basta somente planejar. É preciso que o planejamento seja implementado no processo de gestão. Assim, o planejamento só tem eficácia se servir de subsídio para a gestão ambiental e territorial. Unir planejamento e gestão, incluindo ações de monitoramento, é fundamental. Entretanto, para efetivar este tripé é preciso vontade política, isto é, que os governantes percebam a importância de investir em equipamentos, materiais e recursos humanos que permitam executar esse processo contínuo de planejamento, gestão e monitoramento. Assim, além da dimensão técnica e científica, a dimensão política surge novamente como objeto de análise e de ação. Aliar as dimensões técnica, científica e política é algo fundamental para qualificar a gestão.

2.4.2 Análises de empreendimentos e atividades com potencial de impacto ambiental e dos próprios estudos destinados ao licenciamento ambiental

Outra grande frente de pesquisas ambientais com potencial de desenvolvimento no Brasil, diz respeito às chamadas avaliações de impactos ambientais, sejam elas decorrentes da atuação específica de determinado empreendimento (usina hidrelétrica, loteamento, indústria), sejam de atividades que não estão necessariamente ligadas a empreendimento específico, mas que apresentam algum impacto ambiental (atividades agrícolas, desmatamento, lançamento de efluentes).

De forma geral, qualquer empreendimento ou ação antropogênica tende a causar impacto ambiental a partir do momento em que o fluxo de energia e matéria no sistema é modificado. A utilização de diversos recursos da natureza (água, solos, árvores, minérios), para finalidades diversas, implica que o estamos alterando e, consequentemente, alterando a sua dinâmica natural.

Algo relevante para pesquisas de pós-graduação seria analisar como vem ocorrendo o processo de planejamento e gestão ambiental e territorial no Brasil. Historicamente, predomina no Brasil uma gestão cujo planejamento não tem base, focada em ações de curto prazo e que 
não considera os possíveis impactos sociais e ambientais em médio e longo prazo. A gestão geralmente é feita a partir de interesses políticos e econômicos de determinados indivíduos, grupos ou setores da economia.

Não obstante, quando há algum tipo de planejamento, ele costuma ser contratado em virtude de exigências legais e, muitas vezes, é feito simplesmente para cumpri-las, sem preocupação com a qualidade técnica da equipe responsável por sua realização, sem integração das informações e sem participação popular (OLIVEIRA, 2012).

Outro problema diz respeito à aplicação dos planos e a outras ferramentas do planejamento. Como é comum a realização de planos para atender a alguma legislação ou exigência, muitas vezes após cumpridas essas exigências os planos são engavetados e não são considerados no processo de gestão. Portanto, frente importante para as pesquisas ambientais está na análise crítica de planos, estudos e outros instrumentos de planejamento ambiental, como licenciamentos ambientais, planos diretores municipais, estudos de impacto ambiental e relatórios de impacto ambiental.

Além das análises de impactos ambientais, é preciso pensar e implementar alternativas de uso conservacionista, que envolvem pesquisas e ações de extensão. Na sequência, procuraremos apontar algumas possibilidades nesse contexto.

2.4.3 Análise e implantação de ações voltadas à preservação e usos conservacionistas da natureza e de seus recursos

Conforme avançam descobertas científicas sobre determinados princípios ativos e possibilidades de utilização de elementos bióticos e abióticos da natureza, novas justificativas vão sendo incorporadas no tocante a preservação e usos conservacionistas dos ecossistemas brasileiros. Mesmo considerando de suma importância as ações preservacionistas e, mormente, conservacionistas, independentemente de seu potencial de uso ou uso efetivo, a descoberta de novos produtos (medicamentos, cosméticos, matérias-primas em geral, fontes de energia 
etc.) pode contribuir para maior prudência diante da degradação dos ecossistemas brasileiros.

Sabe-se que as possibilidades de usos conservacionistas e de ações preservacionistas são amplas, portanto procuramos aqui elencar algumas que consideramos relevantes. A análise de situações concretas já existentes, bem como a busca pela expansão quantitativa e qualitativa dessas situações, pode ser objeto de pesquisas da pós-graduação. A partir de análises sobre os avanços e dificuldades dessas iniciativas, é possivel evoluir na implantação de novas iniciativas. Ao conhecer os problemas das experiências concretas, podemos otimizar e melhorar as ações futuras.

Entendemos ser pertinente expandir e qualificar ações para o desenvolvimento da agricultura orgânica e, principalmente, da Agroecologia ${ }^{9}$. Além de não utilizar agroquímicos e transgênicos, a agroecologia é fundamentada na diversificação produtiva das unidades familiares, na autonomia política dos agricultores familiares e em gestão ambiental que alie produção de alimentos e conservação dos ecossistemas. Existem experiências salutares de agroecologia no Brasil, porém é preciso avaliar os avanços e dificuldades enfrentados por aqueles que têm atuado nessa área eminentemente interdisciplinar.

Além da agroecologia, chamamos a atenção para os Sistemas Agroflorestais (SAF), que permitem manejar áreas de florestas, inclusive Reservas Legais e algumas Áreas de Preservação Permanentes, por combinação entre produção, extrativismo e manutenção de áreas florestadas (GÖTSCH, 1997; PORRO, 2009). Essas duas grandes estratégias podem contribuir para produção de alimentos livres de agrotóxicos, obtenção de renda, conservação de áreas florestadas e de seus ecossistemas, diversificação produtiva por parte de agricultores familiares, e fortalecimento da autonomia de agricultores familiares, entre outros benefícios ambientais e sociais.

O manejo agroecológico e o agroflorestal de frutos, sementes,

9 Para mais informações sobre a Agroecologia, ver Altieri (2000; 2009), Gliessmann (2001) e Meira e Candiotto (2014) flores e mel, entre outros produtos oriundos de espécies nativas, são fundamentais para reestabelecer a biodiversidade nos ecossistemas brasileiros e expandir os usos conservacionistas. Para tanto, além da 
manutenção de ecossistemas pouco transformados, seria importante ampliar as estratégias de recomposição florestal e de repovoamento da fauna com espécies nativas. O levantamento da localização e da quantidade de indivíduos de espécies exóticas, principalmente invasoras, é fundamental para definição de ações voltadas à sua paulatina eliminação e para expansão do plantio e inserção de espécies nativas da fauna e da flora.

Pesquisas que analisem, discutam e apontem formas de transformar resíduos em recursos também são relevantes. Quando se utiliza novamente algo que seria descartado ou quando se transformam resíduos sólidos em outro material, na forma de reciclagem, há benefício duplo, pois se reduzem a quantidade de resíduos sólidos gerados e a demanda por novos recursos naturais.

A otimização no uso da energia e da água mediante as chamadas ecotécnicas é outro ponto que pode derivar em novas pesquisas. Técnicas baratas e, ao mesmo tempo, eficientes podem ser usadas na utilização de fontes renováveis de energia (solar, eólica, geotérmica e biomassa), na redução do desperdício de água e no controle da disposição e do lançamento de efluentes, principalmente do esgoto humano e animal.

O turismo em áreas rurais e naturais também se inclui no contexto dos usos conservacionistas. Outrossim, as pesquisas nessa temática devem procurar identificar os aspectos positivos e negativos desse tipo de atividade, nos planos ambiental e social, de forma crítica (CANDIOTTO, 2007).

As unidades de conservação de proteção integral e de uso sustentável possuem importância significativa no Brasil, devido à forte pressão exercida pela exploração desordenada dos ecossistemas brasileiros. Pesquisas relacionadas a esses espaços legalmente protegidos - como a análise de avanços e dificuldades em seu processo de gestão, a otimização da gestão, a atualização de planos de manejo ou a definição de metodologias e critérios para a criação de novas unidades de conservação - também são pertinentes. 


\section{CONSIDERAÇÕES FINAIS}

Destacamos neste artigo a importância da ciência para o avanço de estudos e de ações efetivas de redução da degradação ambiental, bem como de melhorias e ampliação de preservação dos ecossistemas e de promoção de ações conservacionistas. Todavia, ressaltamos a relevância de levar em consideração a dimensão política, aliada às dimensões científica e técnica, para o avanço de processo de planejamento e gestão dos ecossistemas em todo o território brasileiro.

A partir da seleção e apresentação de três eixos de possível atuação, alertamos para a pertinência de se conhecerem e verificarem os erros e acertos no processo de ocupação e gestão ambiental no Brasil. Entendemos que levantar os erros não serve somente para ampliar as análises críticas sobre a questão ambiental, mas também para propor usos mais adequados, bem como técnicas e métodos de implementação desses usos.

Acreditamos que os pesquisadores devem se preocupar com a realização de experimentos e análises que contribuam para indicar caminhos futuros em termos de pesquisa e ação direta. Sabemos que, entre propor e implementar alguma ação, há um caminho longo e não dependente só do pesquisador, de modo que, se uma pesquisa acadêmica tiver como principal objetivo implementar algo proposto, há risco grande de que não se obtenha êxito.

Colocar em prática determinados conhecimentos científicos depende, muitas vezes, da viabilidade econômica (garantia de geração de lucros) e da vontade política dos gestores. Entretanto, é preciso buscar reduzir a dependência da ciência aos interesses políticos e econômicos que limitam o desenvolvimento científico no Brasil, em qualquer área do conhecimento. 


\section{Referências}

AB'SABER, A. Ecossistemas do Brasil. 1. ed. São Paulo: Metalivros, 2006.

Os domínios de natureza no Brasil: potencialidades paisagísticas.

1. ed. São Paulo: Ateliê, 2003.

ACADEMIA DE CIÊNCIAS DO ESTADO DE SÃO PAULO - ACIESP. Glossário de ecologia. 2. ed. São Paulo: Aciesp; CNPq; Finep; Fapesp, 1997.

ALIER, J. M. $\mathbf{O}$ ecologismo dos pobres: conflitos ambientais e linguagens de valoração. 2. ed. São Paulo: Contexto, 2015.

ALTIERI, M. Agroecologia: a dinâmica produtiva da agricultura sustentável. 2. ed. Porto Alegre: UFRGS, 2000.

. El estado del arte de la agroecología: revisando avances y desafíos. In: ALTIERI, M. (Org.). Vertientes del pensamiento agroecológico: fundamentos y aplicaciones. Medellín: SOCLA, 2009. p. 69-95.

AMIN, S. A economia política do século XX. In: ARBIX, G.; ABRAMOVAY, R.; ZALBOVICIUS, M. (Org.). Razões e ficções do desenvolvimento. 1. ed. São Paulo: Unesp; Edusp, 2001. p. 179-195.

BOHRER, C. B. A.; DUTRA, L. E. D. A diversidade biológica e o ordenamento territorial brasileiro. In: ALMEIDA, F. G.; SOARES, L. A. A. (Org.). Ordenamento territorial: coletâneas de textos com diferentes abordagens no contexto brasileiro. 1. ed. Rio de Janeiro: Bertrand Brasil, 2009. p. 115-155.

BRASIL. Constituição da República Federativa do Brasil de 1988. Brasília, DF: Casa Civil, 1988. Disponível em: <http://www.planalto.gov.br/ccivil_03/ constituicao/constituicaocompilado.htm>. Acesso em: 30 nov. 2016.

. Lei $n^{\circ}$ 4.771, de 15 de setembro de 1965. Institui o novo Código Florestal. Brasília, DF: Casa Civil, 1965. Disponivel em: <http://www. planalto.gov.br/ccivil_03/leis/L4771.htm>. Acesso em: 30 nov. 2016. 
. Lei n 6.938, de 31 de agosto de 1981. Brasília, DF: Casa Civil, 1981. Disponível em <http://www.planalto.gov.br/ccivil_03/LEIS/L6938. htm>. Acesso em: 30 nov. 2016.

. Lei $n^{\circ} 12.651$, de 25 de maio de 2012. Dispõe sobre a proteção da vegetação nativa; altera as Leis nos 6.938, de 31 de agosto de 1981, 9.393, de 19 de dezembro de 1996, e 11.428, de 22 de dezembro de 2006; revoga as Leis nos 4.771, de 15 de setembro de 1965, e 7.754, de 14 de abril de 1989, e a Medida Provisória no 2.166-67, de 24 de agosto de 2001; e dá outras providências. Brasília, DF: Casa Civil, 2012. Disponível em: <http://www.planalto.gov.br/ccivil_03/_ato2011-2014/2012/lei/ |12651.htm/>. Acesso em: 30 nov. 2016.

CANDIOTTO, L. Z. P. A perspectiva dialética no uso dos recursos naturais e a abordagem territorial como elemento de interpretação de dinâmicas socioambientais. Terra Livre, São Paulo, v. 2, n. 41, p. 133-168, 2013.

Turismo rural na agricultura familiar: uma abordagem geográfica do Circuito Italiano de Turismo Rural (CITUR), município de Colombo - PR. 2007. Tese (Doutorado em Geografia) - Centro de Filosofia e Ciências Humanas, Universidade Federal de Santa Catarina, Florianópolis.

CUNHA, L. H.; COELHO, M. C. N. Política e gestão ambiental. In: CUNHA, S. B.; GUERRA, A. J. T. (Org.). A questão ambiental: diferentes abordagens. 1. ed. Rio de Janeiro: Bertrand Brasil, 2003. p. 43-79.

DEAN, W. A ferro e fogo: a história e a devastação da mata atlântica brasileira. 1. ed. São Paulo: Companhia das letras, 1996.

DIEGUES, A. C. 0 mito moderno da natureza intocada. 1. ed. São Paulo: Hucitec, 1994.

FUNDAÇÃO DE AMPARO À PESQUISA DO ESTADO DE SÃO PAULO FAPESP. Revisão sem sustentação científica. Agência Fapesp. 19 jul. 2010. Disponível em: <http://agencia.fapesp.br/revisao_sem_sustentacao_ cientifica/12481/>. Acesso em: 30 nov. 2016. 
GLIESSMAN, S. R. Agroecologia: processos ecológicos em agricultura sustentável. 2. ed. Porto Alegre: UFRGS, 2001.

GÖTSCH, E. Homem e natureza: cultura na agricultura. 2. ed. Recife: Centro de Desenvolvimento Agroecológico Sabiá, 1997.

GUDYNAS, E. Ecología, economía y etica del desarrollo sostenible. 5. ed. Montevideo: CLAES, 2004.

HAESBAERT, R. 0 mito da desterritorialização. 1. ed. Rio de Janeiro: Bertrand Brasil, 2004.

LEFF, E. Ecología y capital: racionalidad ambiental, democracia participativa y desarrollo sustentable. 3. ed. México: Siglo Veintiuno, 1998.

MEIRA, S. G.; CANDIOTTO, L. Z. P. Agricultura orgânica: uma proposta de diferenciação entre estabelecimentos rurais. Campo-Território - Revista de Geografia Agrária, Uberlândia, v. 9, n. 19, out, p. 149-176, 2014.

MILARÉ, É. Direito do ambiente: a gestão ambiental em foco - doutrina, jurisprudência, glossário. 5. ed. São Paulo: Revista dos Tribunais, 2007.

OLIVEIRA, V. B. Licenciamento ambiental: estamos escrevendo nada para ninguém. Portal EcoDebate, Rio de Janeiro, jan. 2012. Disponível em <http://www.ecodebate.com.br/2012/01/03/licenciamento-ambientalestamos-escrevendo-nada-para-ninguem-artigo-de-valeska-buchemide-oliveira>. Acesso em: 2330 nov. 2016.

PORRO, R. Alternativa agroflorestal na Amazônia em transformação. 1. ed. Brasília, DF: Embrapa Informação Tecnológica, 2009.

PORTO-GONÇALVES, C. W. P. A globalização da natureza e a natureza da globalização. 4. ed. Rio de Janeiro: Civilização Brasileira, 2012.

RAFFESTIN, C. Por uma geografia do poder. 1. ed. São Paulo: Ática, 1993.

ROSS, J. Ecogeografia do Brasil: subsídios para o planejamento ambiental. 1. ed. São Paulo: Oficina de Textos, 2003. 
SANTOS, M. A natureza do espaço. 1. ed. São Paulo: Hucitec, 1996.

SOUZA, M. L. O território: sobre espaço e poder, autonomia e desenvolvimento. In: CASTRO, I. E.; GOMES, P. C. C.; CORRÊA, R. L. (Org.). Geografia: conceitos e temas. 1. ed. Rio de Janeiro: Bertrand Brasil, 1995. p. 77-116.

Recebido em 29/04/2016 Aprovado em 03/10/2016 